\title{
Optimization of Current Total Harmonic Distortion in Series-Connected Rectifiers
}

\author{
N.Yousefpoor, G.B.Gharehpetian, S.H.Fathi \\ Department of Electrical Engineering, Amirkabir University of Technology, Tehran, Iran \\ E-mail: nimayousefpoor@aut.ac.ir, grptian@aut.ac.ir, fathi@aut.ac.ir
}

\begin{abstract}
An innovative method for reducing current total harmonic distortion on the AC side of twelve-pulse series connected AC/DC rectifiers is simulated in this paper. The principle of the method is to modify the current waveforms on the DC side of the converter by using self-commutated switches. An averaging inductor is added to the series connected converters and thus simplifies the pulse multiplication significantly. This method can make a 12-pulse double bridge converter to operate at 24,36 and 48 pulses. A reinjection transformer is also used in series-connected converters to reinject a current to the main rectifier. Minimum value for the total harmonic distortion of AC current can be achieved by selecting an appropriate value for turn ratio of reinjection transformer. Genetic Algorithm (GA) has been used to calculate the optimal value for turn ratio of reinjection transformer. The total harmonic distortion of AC current has been calculated for different values of the turn ratio of reinjection transformer, and the minimum value of THD is obtained at turn ratio of reinjection transformer calculated by GA for 24,36 and 48-pulse operation modes.
\end{abstract}

Index Terms-HVDC Systems, Reinjection Transformer, Harmonic Optimization, Genetic Algorithm (GA) and 36-Pulse Series-Connected Rectifiers.

\section{INTRODUCTION}

HVDC converter stations are normally designed for 12-pulse operation, with such an arrangement being a source of current harmonics on the AC side [1]. The inherent distortion of currents on the AC side, however, contributes to increased distribution losses and degrades the quality of the electrical supply [2]. To maintain the supply quality at acceptable levels, national standards specify limits for the current distortion generated. Thus, the need for new and innovative methods to reduce current distortion exists. Passive filters are conventionally used to diminish the harmonics. Filters, however, apart from their complicated design and transient nature, constitute a considerable part of the volume and cost of present DC terminal stations, and thus any possible new alternative is welcome.

Several attempts have been made to find suitable alternatives to filters. The basic principle of shunt active filters was a concept that has greatly developed in recent years [1], providing flexibility to even remove uncharacteristic harmonics. Increasing the number of pulses or phases of the rectifier could reduce the harmonics but are not practical because of the cost and size of added thyristors and phase transformers. Various schemes for reducing the
AC side current harmonics have been proposed by different investigators. The first approach toward these techniques was carried out by adding a harmonic current from an external source, which was avoided in later developments. The ripple voltage at the DC terminal is directly used in many new methods to produce the reinjection current [4].

Pulse multiplication methods in both parallel and series connected converters have been proposed. The configuration for a parallel-connected pulse multiplication method is much simpler than a series-connected scheme. This method, however, can only be applied to the rectifier with an interphase transformer. Series-connected rectifiers make use of a reinjection transformer and a switching circuit to reinject a current to the main rectifier circuit [3]. The turn ratio of reinjection transformer can be considered as a variable and minimum value for the total harmonic distortion of AC current can be achieved by selecting an appropriate value for turn ratio of reinjection transformer. An averaging inductor which has a lot of advantages is used in this method. The main advantage of this method is that high-pulse multiplication can be easily achieved. In this paper, genetic algorithm is used to calculate the optimal value of the turn ratio of reinjection transformer for 24, 36 and 48-pulse operation modes. Simulation is also carried out to show the validity of theoretical results.

\section{CIRCUIT CONFIGURATION}

The configuration for a 36-pulse double bridge converter is shown in Fig. 1. The averaging inductor shown in this figure functions similar to the interphase transform in a parallel-connected converters. The reinjection circuit uses three switching thyristors and as a result the effective pulse numbers will be tripled. Harmonic level will also be reduced to about one third of that of the original system [4].

This configuration uses three switching thyristors to achieve 36-pulse operation. However, this method is not restricted to three switching thyristors. Fig. 2 shows the cases of two switching thyristors. In this case, the converter operates at 24 pulses (output voltage). Fig. 3 shows the switching circuit construction of four switching thyristors and thus the converter operates at 48 pulses in this case.

\section{INPUT CURRENT ON THE AC SIDE}

The current flow of this method for 36-pulse series converters is shown in Fig. 4. Current values of the two secondary windings of the converter transformers are 
distinguished by subscripts of “ 1 " and “2”. By proper firings of $T_{1}-T_{3}$, the output voltage will have three pulses every 30 electrical degrees, or 36 pulses per cycle. The switching pattern of $T_{1}-T_{3}$ are shown in Fig. 5.

\section{A. Current without reinjection}

Each current in the case of no reinjection will be denoted by adding a subscript " 0 ". The waveforms of $i_{a 10}$ and $i_{a 20}$ are shown in Fig. 6(a). The two secondary winding line currents have the same waveform but phase-shifted by $30^{\circ}$. The primary winding line current relates to the secondary currents by: $i_{\mathrm{A}}=\frac{\mathrm{N}_{2}}{\mathrm{~N}_{1} \sqrt{3}}\left(i_{\mathrm{a} 1}-i_{\mathrm{c} 1}\right)+\frac{\mathrm{N}_{2}}{\mathrm{~N}_{1}} i_{\mathrm{a} 2}$

The waveform of iA0 is shown in Fig. 6(b). This current waveform has 12 steps in each cycle.

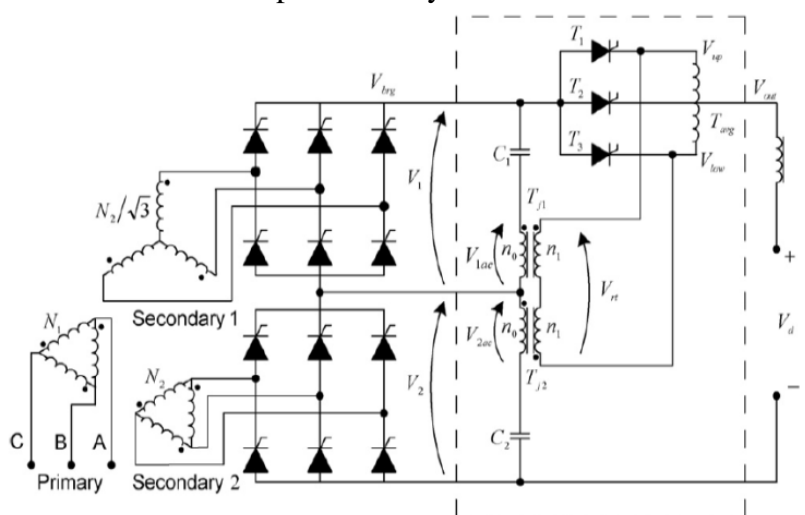

Fig. 1 Circuit configuration for 36-pulse series converters [4]

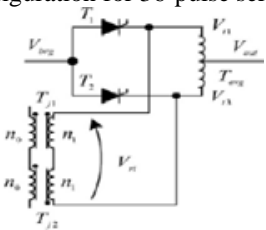

Fig. 2 Switching circuit configuration for 24-pulse series converters [4]

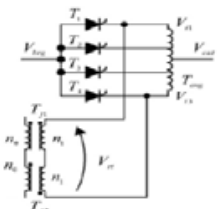

Fig. 3 Switching circuit configuration for 48-pulse series converters [4]

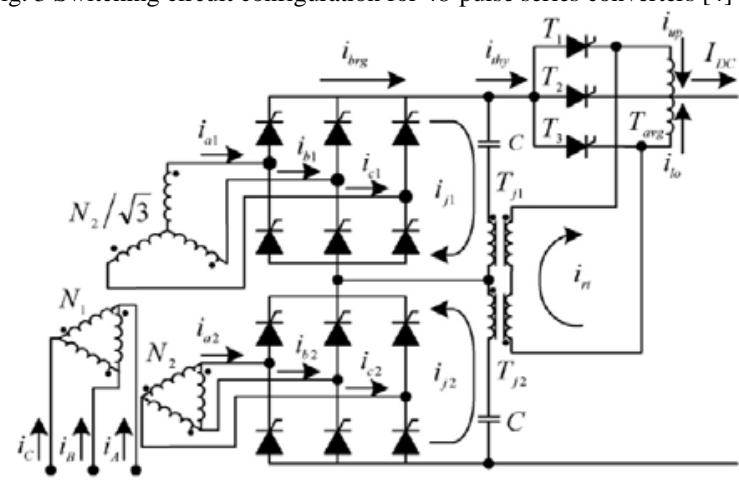

Fig. 4 Current flow [4]

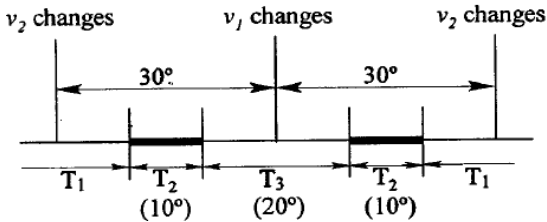

Fig. 5 Firing of thyristors $T_{1}-T_{3}$
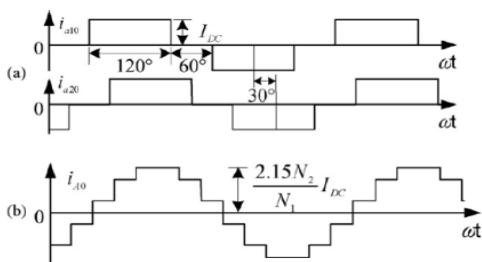

Fig. 6 Current waveforms without reinjection (a) $i_{a 10}, i_{a 20}$ and (b) $i_{A 0}$

\section{B. Current with reinjection}

During $T_{1}$ or $T_{3}$ conduction, the following relationship exists as it can be seen from Fig. 4:

$I_{\text {DC }}=\mathrm{i}_{\text {up }}+\mathrm{i}_{\text {lo }}$

The tap is in the middle of the averaging inductor and $i_{\text {out }}$ is constant, as follows:

$\mathrm{i}_{\text {up }}=\mathrm{i}_{\text {lo }}=0.5 I_{\text {DC }}$

No current flows in the inductor when $T_{2}$ conducts. By using the current directions shown in Fig. 4, it can be seen that:

$\mathrm{i}_{\mathrm{rt}}= \begin{cases}-\mathrm{i}_{\mathrm{lo}}=-0.5 I_{\mathrm{DC}} & T_{1} \text { On } \\ 0 & T_{2} \text { On } \\ \mathrm{i}_{\mathrm{up}}=0.5 I_{\mathrm{DC}} & T_{3} \text { On }\end{cases}$

$\mathrm{i}_{\mathrm{j} 1}=\mathrm{i}_{\mathrm{j} 2}=\frac{n_{1}}{\mathrm{n}_{0}} \mathrm{i}_{\mathrm{rt}}=\mathrm{k} \cdot \mathrm{i}_{\mathrm{rt}}$

$\mathrm{i}_{\mathrm{j} 1}=\mathrm{i}_{\mathrm{j} 2}= \begin{cases}-0.5 \mathrm{k} I_{D C} & T_{1} \text { On } \\ 0 & T_{2} \text { On }\end{cases}$

$\mathrm{i}_{\text {brg }}=\mathrm{i}_{\text {thy }}+\mathrm{i}_{\mathrm{j} 1}=I_{\mathrm{DC}}+\mathrm{i}_{\mathrm{j} 1}$

$\mathrm{i}_{\text {brg }}= \begin{cases}(1-0.5 \mathrm{k}) I_{\mathrm{DC}} & T_{1} \text { On } \\ I_{\mathrm{DC}} & T_{2} \text { On } \\ (1+0.5 \mathrm{k}) I_{\mathrm{DC}} & T_{3} \text { On }\end{cases}$

The current waveforms of $i_{j 1}$ and $i_{b r g}$ are shown in Figs. 7 (a) and (b). Eq. (8) indicates clearly that the reinjection current $i_{j 1}$ is superimposed to the original converter current. The flow of $i_{j 1}$ reflects back to the primary side of the converter transformer and cancels out a portion of the harmonics in the original current $i_{A 0}$. The commutation of the main bridge is independent of the current reinjection, so the transformer secondary currents can be found conveniently from the modified $i_{b r g}$. Their waveforms are shown in Fig. 7(c). The line current of the primary winding relates to $i_{a 1}$ and $i_{a 2}$ by Eq. (1). The waveform of $i_{A}$ is shown in Fig. 7 (d).

\section{Harmonics of AC Line current}

From the Fourier analysis of the input AC line current, $i_{A 0}$ shown in Fig. 6 can be expressed by the following equations:

$i_{\mathrm{A} 0}=\frac{4 \sqrt{3} \mathrm{~N}_{2}}{\pi N_{1}} I_{\mathrm{DC}} \times\left[\sin (\omega t)+\sum_{h=1}^{\infty} \frac{1}{12 h \pm 1} \sin ((12 h \pm 1) \omega t)\right]$

Similarly $i_{A}$ can be written as follows:

$i_{\mathrm{A}}=\frac{16 \sqrt{3} \mathrm{~N}_{2}}{\pi \mathrm{N}_{1}} I_{\mathrm{DC}} \sin \left(\frac{\pi}{12}\right)+\left[A_{1} \sin (\omega t)+\sum_{h=1}^{\infty} \frac{(-1)^{h}}{12 h \pm 1} A_{12 h \pm 1} \sin ((12 h \pm 1) \omega t)\right]$

Where

$A_{12 h \pm 1}=\frac{\mathrm{k}}{2} \cos \left[\frac{(12 h \pm 1) \pi}{36}\right]+\left(1-\frac{\mathrm{k}}{2}\right) \cos \left[\frac{(12 h \pm 1) \pi}{12}\right]$

For $P$-pulse operation mode, Eq. (11) can be rewritten as follows:

$A_{12 h \pm 1}=\frac{\mathrm{k}}{2} \cos \left[\frac{(12 h \pm 1) \pi}{P}\right]+\left(1-\frac{\mathrm{k}}{2}\right) \cos \left[\frac{(12 h \pm 1) \pi}{12}\right]$

Where $P$ is the pulse number ( $P=24$ or 36 or 48 ).

The optimum turns ratio $(k)$ should be chosen to minimize the total harmonics distortion expressed by the following equation:

$T H D(k)=\sqrt{\sum_{h=1}^{\infty}\left[\frac{A_{12 h \pm 1}}{(12 h \pm 1) A_{1}}\right]^{2}}$ 
In this paper, Genetic Algorithm (GA) is used to calculate the optimal value for the turn ratio of the reinjection transformer for 24, 36 and 48-pulse operation modes.

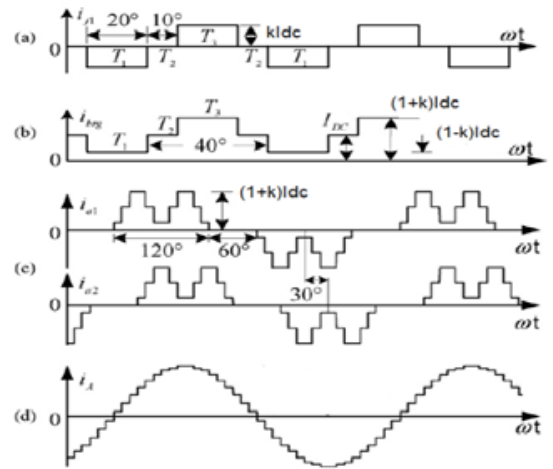

Fig. 7 Current waveforms with reinjection (a) $i_{j 1}$ (b) $i_{b r g}$ (c) $i_{a 1}, i_{a 2}$ (d) $i_{A}$

\section{GENETIC ALGORITHM RESULTS}

Genetic Algorithms (GAs) are powerful stochastic global search and optimization algorithms, based on the principles of natural genetics. These algorithms provide global near-optimal solutions of Fitness function by striking a remarkable balance between exploration and exploitation in complex, large and multi-modal landscapes.

In this problem, the turn ratio of reinjection transformer which should be determined is called a gene. A chromosome consists of all the genes and in this case there is one gene in one chromosome. Thus, each chromosome represents a possible solution to the problem. The population consists of a finite set of chromosomes. A chromosome is developed based on single dimensional arrays.

Initialization of the Population is necessary for any GA. The most common method is to randomly generate solutions for the entire population. Evaluation of Fitness function is an important step in GA. The selection of parents to produce successive generations plays a key role in the GA, too. Crossover and Mutation are the two basic types of genetic operators used in this paper. The GA moves from generation to generation selecting and reproducing parents until a termination criterion is met.

GA is applied to compute the optimal value of the turn ratio of the reinjection transformer $(k)$ for 24,36 and 48-pulse operation modes. The objective function is the Eq. (13), and the results are as follows:

$P=24: k=1.46947, T H D=6.04 \%$

$P=36: k=1.30756, T H D=5.09 \%$

$P=48: k=1.22685, T H D=5.3 \%$

\section{SIMULATION RESULTS}

The 12-pulse series-connected rectifier without reinjection transformer is simulated by Matlab/Simulink. The results are shown in Figs. 8-12.

The AC line current in series-connected rectifiers without reinjection is shown in Fig. 8. The total harmonic distortion (THD) of AC line current is 15.22\%. The converter DC output voltage, $V_{b r g}$, has 12 pulses as shown in Fig. 11, where each pulse lasts for $30^{\circ}$. It is equal to the addition of the two bridges output voltages $V_{1}$ and $V_{2}$. Voltages $V_{1}$ and $V_{2}$ have exactly the same waveform but phase-shifted by $30^{\circ}$ as shown in Figs. 9 and 10.

Now, 36-pulse series-connected rectifier with reinjection transformer is simulated and the results are shown in Figs. 13-20.

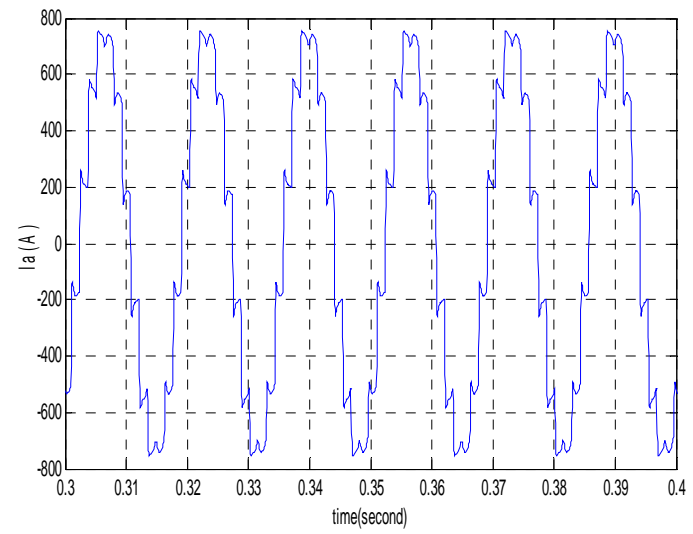

Fig. 8 AC line current without reinjection, $\alpha=15^{\circ}$

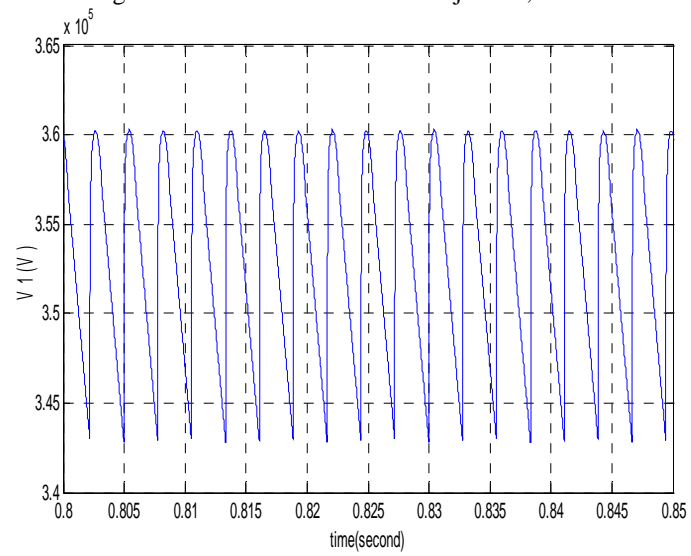

Fig. 9 Voltage $V_{1}$ without reinjection, $\alpha=15^{\circ}$

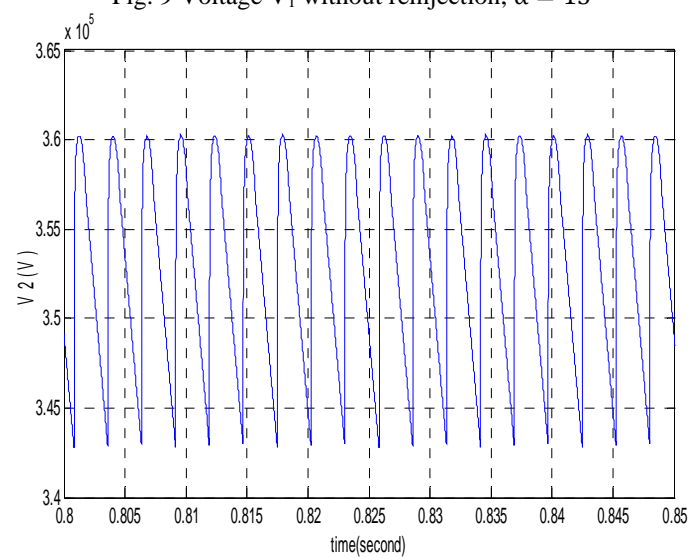

Fig. 10 Voltage $V_{2}$ without reinjection, $\alpha=15^{\circ}$

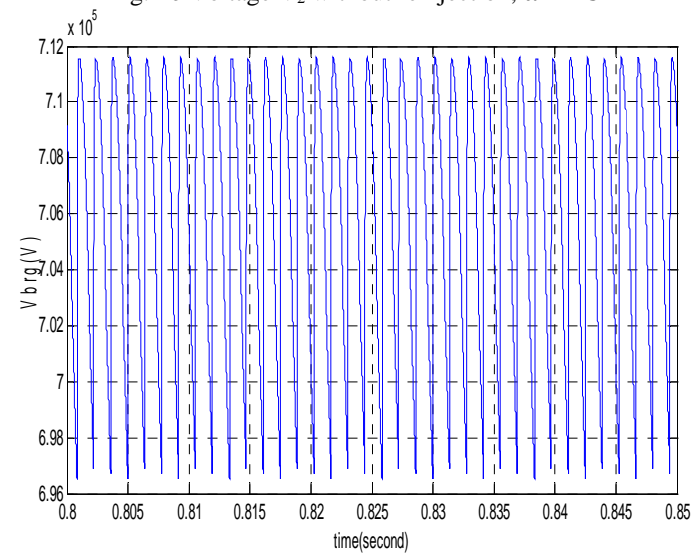

Fig. 11 Voltage $V_{\text {brg }}$ without reinjection, $\alpha=15^{\circ}$ 


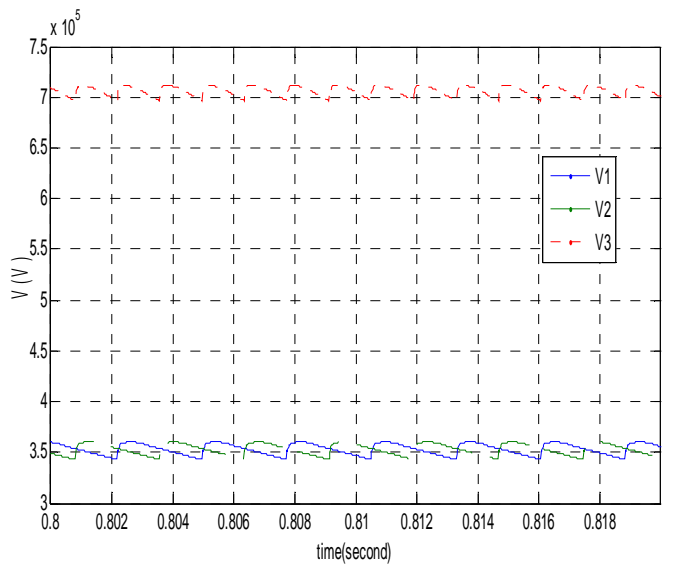

Fig. 12 Comparison of $\mathrm{V}_{1}, \mathrm{~V}_{2}$ and $\mathrm{V}_{\mathrm{brg}}$ without reinjection, $\alpha=15^{\circ}$

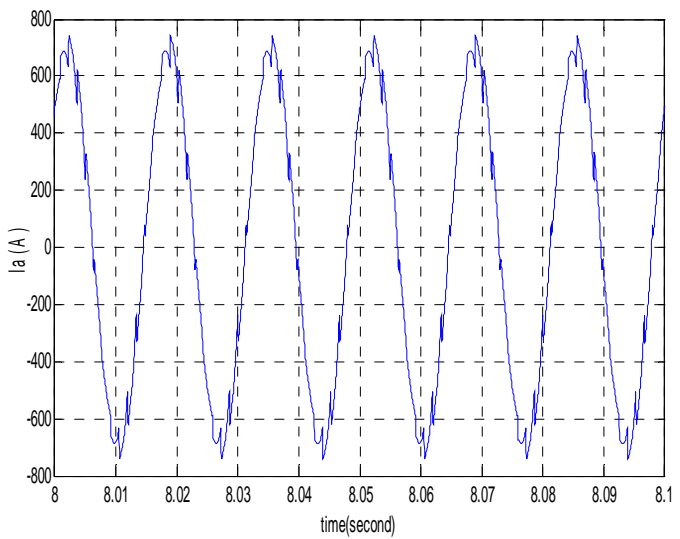

Fig. 13 AC line current with reinjection, $\alpha=15^{\circ}$ (36-pulse)

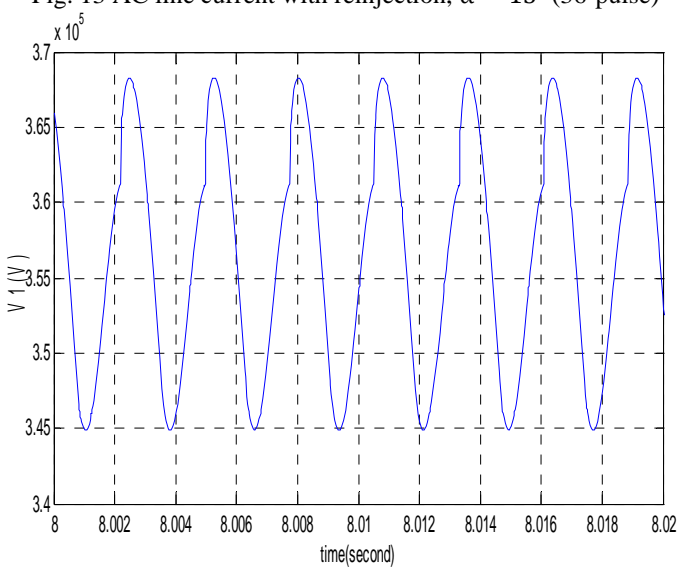

Fig. 14 Voltage $V_{1}$ with reinjection, $\alpha=15^{\circ}$ (36-pulse)

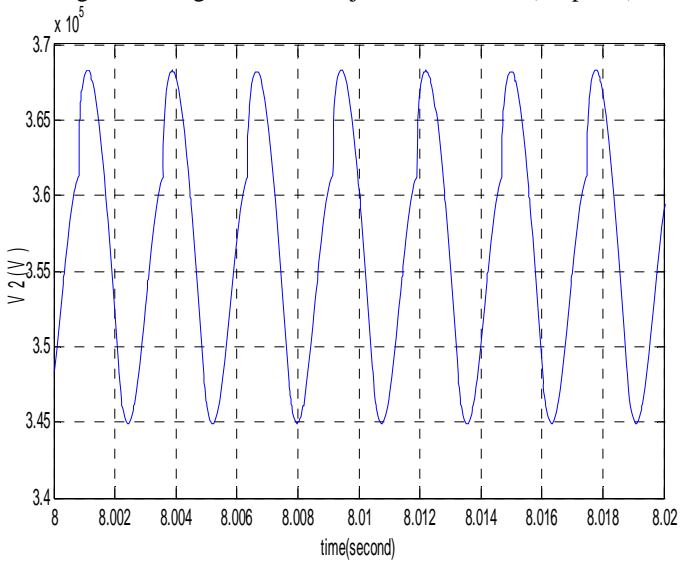

Fig. 15 Voltage $V_{2}$ with reinjection, $\alpha=15^{\circ}$ (36-pulse)

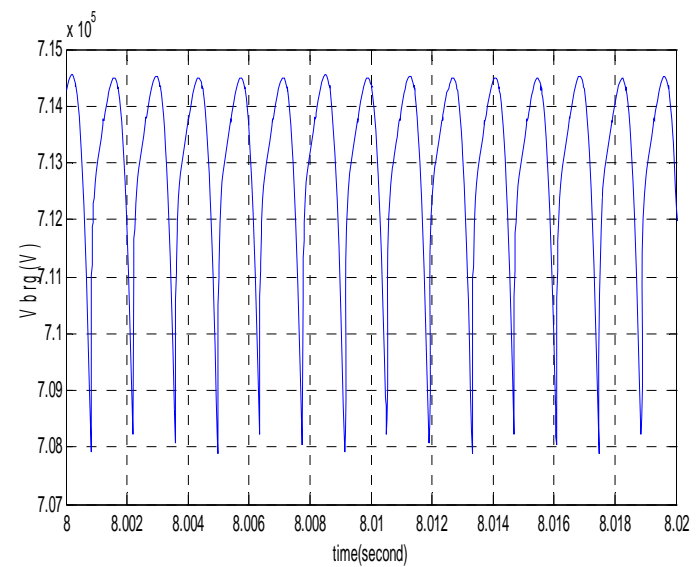

Fig. 16 Voltage $\mathrm{V}_{\mathrm{brg}}$ with reinjection, $\alpha=15^{\circ}$ (36-pulse)

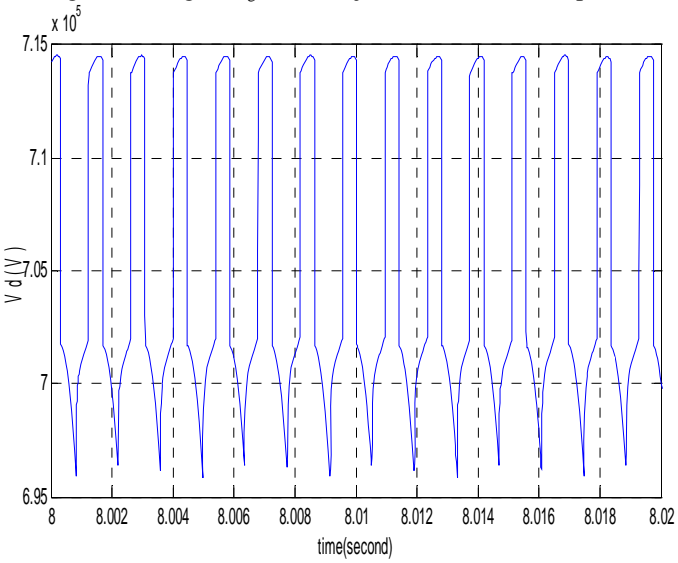

Fig. 17 Output Voltage $V_{d}$ with reinjection, $\alpha=15^{\circ}$ (36-pulse)

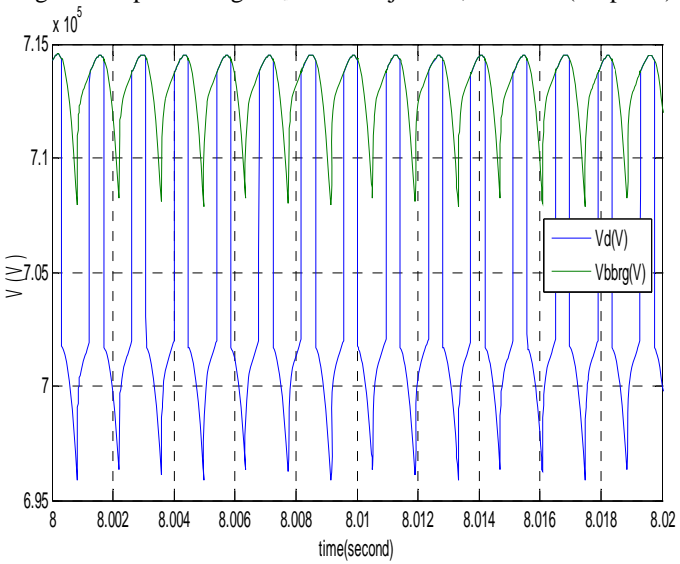

Fig. 18 Comparison of $V_{d}$ and $V_{\text {brg }}$ with reinjection, $\alpha=15^{\circ}$ (36-pulse)

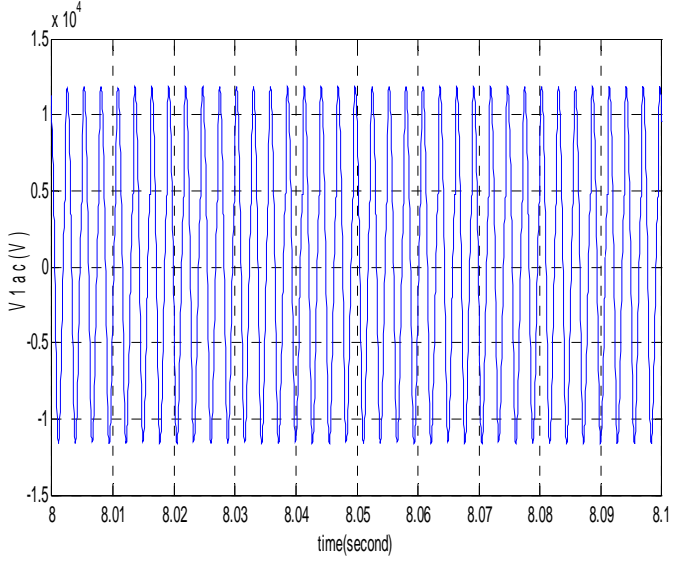

Fig. 19 Voltage $\mathrm{V}_{1 \text { ac }}$ with reinjection, $\alpha=15^{\circ}$ (36-pulse) 


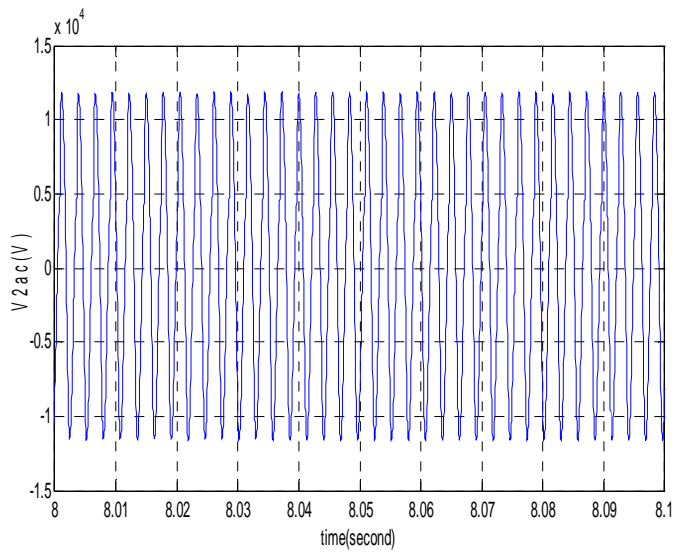

Fig. 20 Voltage $\mathrm{V}_{2 \mathrm{ac}}$ with reinjection, $\alpha=15^{\circ}$ (36-pulse)

The AC line current in 36-pulse series-connected rectifiers with reinjection is shown in Fig. 13. The converter DC output voltage has 36 pulses as shown in Fig. 17, where each pulse lasts for $10^{\circ}$ and $V_{b r g}$, has 12 pulses as shown in Fig. 16 where each pulse lasts for $30^{\circ}$. Comparison of $V_{d}$ and $\mathrm{V}_{\text {brg }}$ is shown in Fig. 18. $\mathrm{V}_{\text {brg }}$ is the addition of the two bridge output voltages $\left(V_{1}\right.$ and $\left.V_{2}\right)$. Voltages $V_{1}$ and $V_{2}$ have exactly the same waveform but phase-shifted by $30^{\circ}$ as shown in Figs. 14 and 15. Because of the DC blocking capacitors, only AC components of the bridge output, namely $V_{1 a c}$ and $V_{2 a c}$, are present on the primary windings of the reinjection transformers $T_{j 1}$ and $T_{j} 2$. These waveforms are shown in Figs. 19 and 20.

By selecting different values for the turn ratio of the reinjection transformer $(k)$ and after simulation for each value of $(k)$, the Total Harmonic Distortion (THD) of AC line current versus $k$ is calculated which is shown in Fig. (21). Results show that the minimum Total Harmonic Distortion (THD) is 5.09\% which happen at $\mathrm{k}=1.30756$ which is as same as the value obtained by GA. (36-pulse)

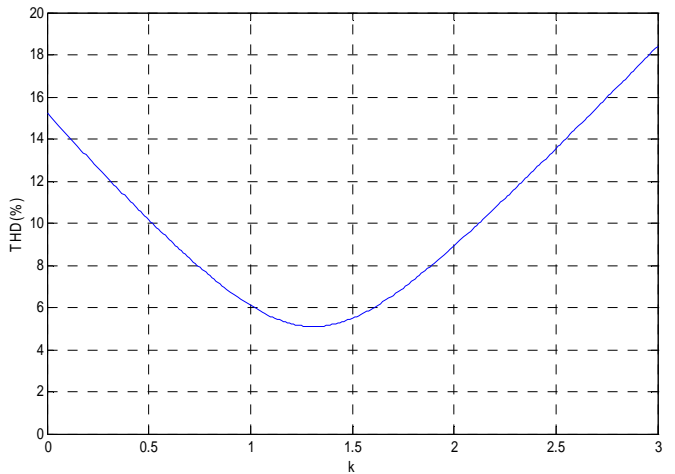

Fig. 21 THD versus $k$ (36-pulse)

The 24-pulse series-connected rectifier with reinjection transformer is also simulated and the results are shown in Figs. 22-24. The AC line current in 24-pulse series-connected rectifiers with reinjection is shown in Fig. 22. $\mathrm{V}_{\mathrm{d}}$ is compared with $\mathrm{V}_{\text {brg }}$ in Fig. 23. The converter DC output voltage has 24 pulses where each pulse lasts for $15^{\circ}$ and $V_{b r g}$ has 12 pulses where each pulse lasts for $30^{\circ}$. $\mathrm{V}_{1}$ is compared with $\mathrm{V}_{2}$ in Fig. 24.

By selecting different values for the turn ratio of the reinjection transformer $(k)$ and after simulation for each value of $(k)$, the Total Harmonic Distortion (THD) of AC line current versus $k$ is calculated which is shown in Fig. (25). Results show that the minimum Total Harmonic Distortion (THD) is 6.04\% which happen at $\mathrm{k}=1.46947$ which is as same as the value obtained by GA. (24-pulse)

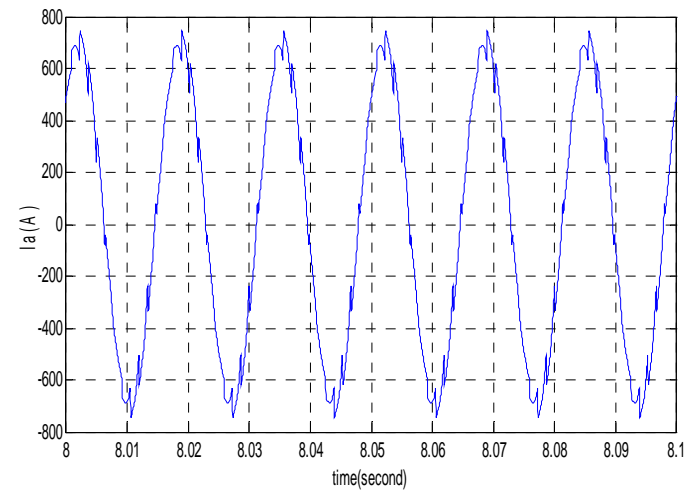

Fig. 22 AC line current with reinjection, $\alpha=15^{\circ}$ (24-pulse)

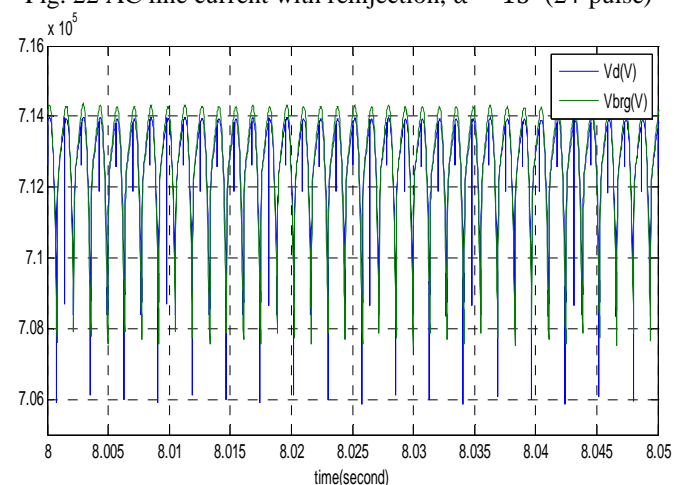

Fig. 23 Comparison of $V_{d}$ and $V_{\text {brg }}$ with reinjection, $\alpha=15^{\circ}$ (24-pulse)

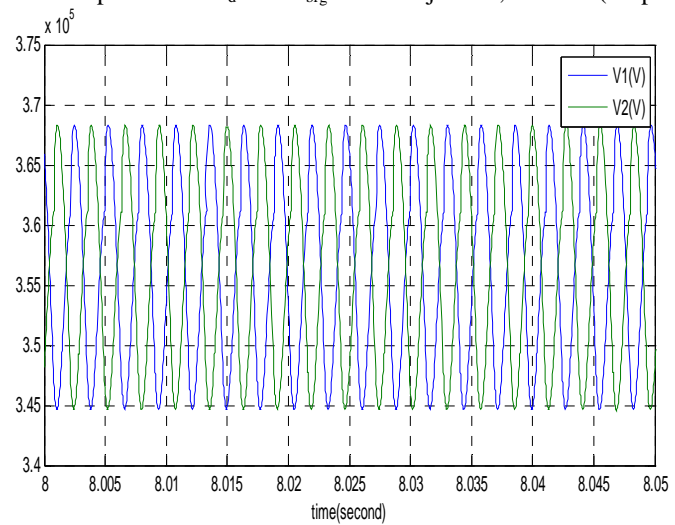

Fig. 24 Comparison of $\mathrm{V}_{1}$ and $\mathrm{V}_{2}$ with reinjection, $\alpha=15^{\circ}$ (24-pulse)

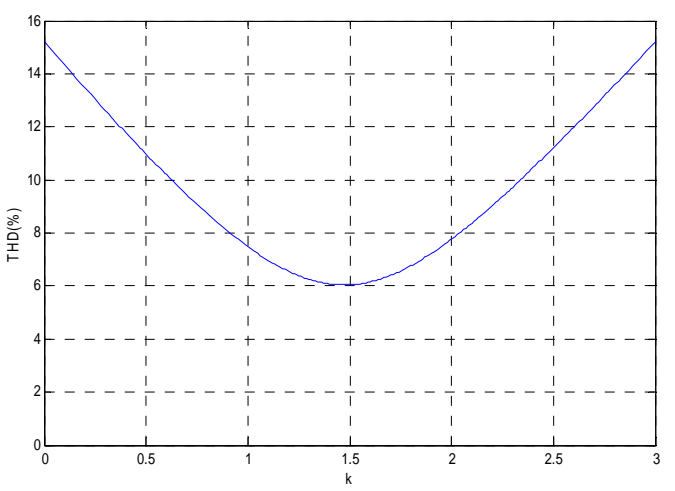

Fig. 25 THD versus $k$ (24-pulse) 
The 48-pulse series-connected rectifier with reinjection transformer is also simulated and the results are shown in Figs. 26-28. The AC line current in 48-pulse series-connected rectifiers with reinjection is shown in Fig. 26. $V_{d}$ is compared with $V_{\text {brg }}$ in Fig. 27. The converter DC output voltage has 48 pulses where each pulse lasts for $7.5^{\circ}$ and $V_{b r g}$ has 12 pulses where each pulse lasts for $30^{\circ}$. $\mathrm{V}_{1}$ is compared with $\mathrm{V}_{2}$ in Fig. 28.

By selecting different values for the turn ratio of the reinjection transformer $(k)$ and after simulation for each value of $(k)$, the Total Harmonic Distortion (THD) of AC line current versus $k$ is calculated which is shown in Fig. (29). Results show that the minimum Total Harmonic Distortion (THD) is 5.3\% which happen at $\mathrm{k}=1.22685$ which is as same as the value obtained by GA. (48-pulse)

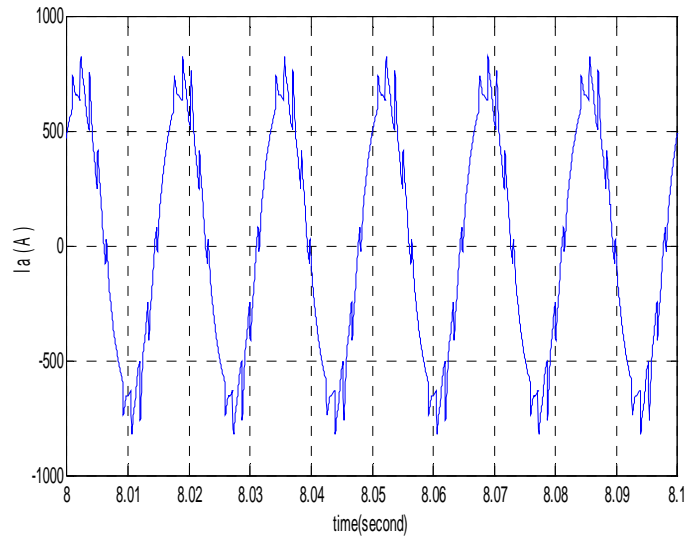

Fig. 26 AC line current with reinjection, $\alpha=15^{\circ}$ (48-pulse)

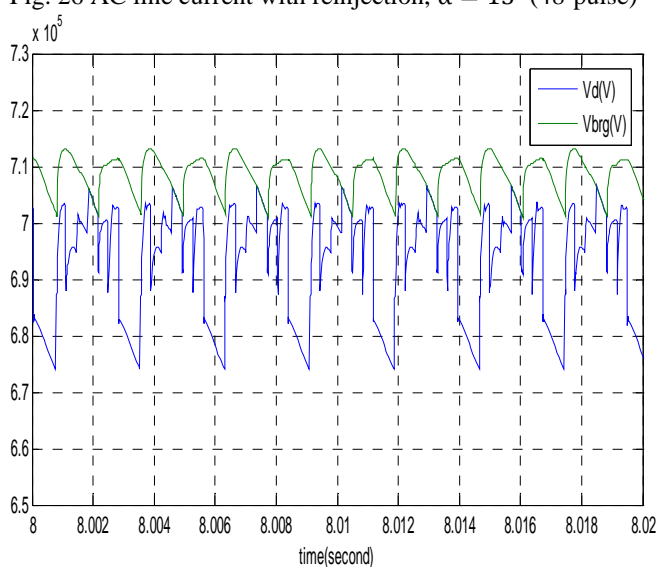

Fig. 27 Comparison of $V_{d}$ and $V_{\text {brg }}$ with reinjection, $\alpha=15^{\circ}$ (48-pulse)

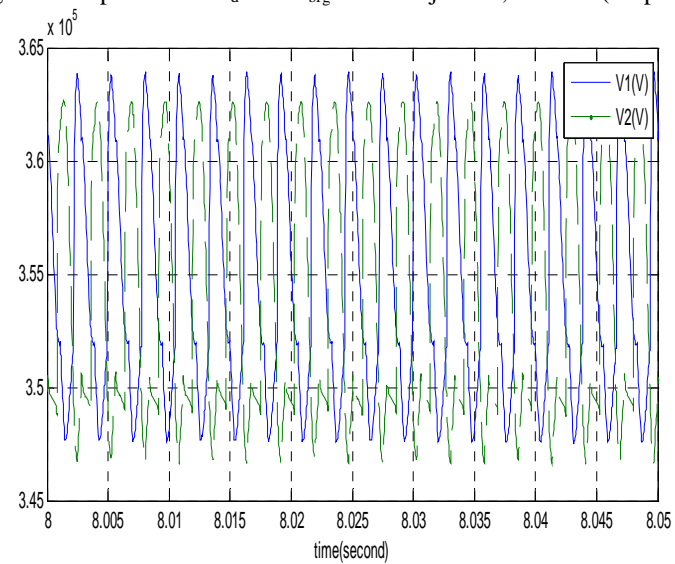

Fig. 28 Comparison of $V_{1}$ and $V_{2}$ with reinjection, $\alpha=15^{\circ}$ (48-pulse)

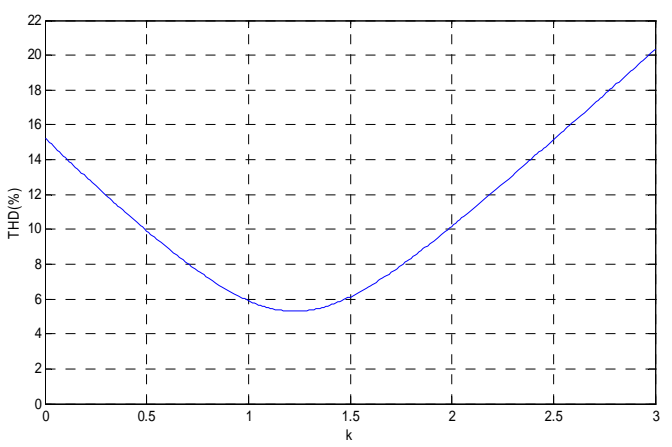

Fig. 29 THD versus $k$ (48-pulse)

\section{CONCLUSION}

An innovative method to reduce the current total harmonic distortion on the AC side of twelve-pulse series connected AC/DC rectifiers has been simulated in this paper. The principle of the method is to modify the current waveforms on the DC side of the converter by using self-commutated switches. Series-connected rectifiers make use of a reinjection transformer and a switching circuit to reinject a current to the main rectifier circuit. The turn ratio of the reinjection transformer can be considered as a variable and minimum value for the total harmonic distortion of AC current can be achieved by selecting an appropriate value for turn ratio of the reinjection transformer. Genetic Algorithm has been used as a powerful tool to calculate the optimal value of the turn ratio of reinjection transformer. In this paper, the method is applied to the converter to change its operation mode to 36, 24 and 48 pulse operation modes. The simulation results have been presented for different operation modes. Minimum total harmonic distortion of AC current can be achieved if the turn ratio of the reinjection transformer $(k)$ is set at the values obtained by GA.

\section{REFERENCES}

[1] M.E.Villablanca, J.D. Rojas, J. Abarca,W. Rojas,Amodified back-toback HVDC system for 36-pulse operation, IEEE Trans. Power Delivery 15 (2) (2000).

[2] M.E. Villablanca, J.I. Nadal, Current Distortion Reduction in SixPulse Parallel-Connected AC/DC Rectifiers, IEEE TRANSACTIONS ON POWER DELIVERY, VOL. 23, NO. 2, APRIL 2008.

[3] M.E. Villablanca, J.D. Valle, C. Urrea, W. Rojas, 36-Pulse HVDC transmission for remotely sited generation, IEEE Trans. Power Delivery 16 (4) (2001).

[4] Kaili Xua, Kala Meah, A.H.M. Sadrul Ula, A novel method for reducing harmonics in series-connected rectifiers, Electric Power Systems Research 78 (2008) 1256-1264.

[5] R.L. Hauth, P.J. Tatro, B.D. Railing, B.K. Johnson, J.R. Stewart, J.L. Fink, HVDC power transmission technology assessment report, ORNL/Sub/95-SR893/1, Oak Ridge National Laboratory, April 1997.

[6] J.F. Baird, J. Arrilaga, Harmonic reduction in D.C.-ripple reinjection. Part C, IEE Proc. 127 (5) (September 1980).

[7] S. Miyairi, S. Iida, K. Nakata, S. Masukawa, New method for reducing harmonics involved in input and output of rectifier with interphase transformer, IEEE Trans. Ind. Appl. IA-22 (5) (September/October 1986).

[8] J. Arrillaga,W. Enright, A.R.Wood, F. Perez Hidalgo, DC Side Harmonic Reduction in HVDC Converters by Direct Ripple Reinjection, 423, IEE Conference Publication, 1996.

[9] M.E. Villablanca, J. Arrillaga, Single-bridge unit-connected HVDC generator with increased pulse number, IEEE Trans. Power Delivery 8 (2) (1993). 